\title{
Crystal engineered hybrid ultramicroporous materials for single-step ethylene purification from $\mathrm{C}_{2}-\mathrm{CO}_{2}$ ternary mixture
}

\author{
Soumya Mukherjee ${ }^{1,2}$, Michael J. Zaworotko² \\ ${ }^{1}$ Department of Chemistry, Technical University of Munich, Lichtenbergstraße 4, 85748 Garching b. Munich, Germany \\ ${ }^{2}$ Bernal Institute, Department of Chemical Sciences, University of Limerick, Limerick V94 T9PX, Republic of Ireland Email of
}

communicating author: soumya.mukherjee@tum.de

Mankind is now in the "age of gas"[1] and there are urgent needs in gas purification that will likely only be solved by a new generation of physisorbent porous materials that offer reduced cost and superior performance. Engaging the principles of crystal engineering, hybrid ultramicroporous materials, HUMs (pore size $<0.7 \mathrm{~nm}$ ) [2], by means of combining small pores $(<0.7 \mathrm{~nm})$ with strong electrostatics offer an ideal sorbent platform suited for tight-fit of the target sorbate, resulting in performance benchmarks over the recent years $[3,4]$. However, due to narrow pore networks imposing steric restrictions, crystal engineering of modular HUMs on account of organic ligand functionalisation has remained largely elusive.

Moving one step ahead of the synergistic sorbent separation technology [5], herein we address single-step purification of ethylene $\left(\mathrm{C}_{2} \mathrm{H}_{4}\right)$, the highest volume product of the chemical industry, by crystal engineering of two HUMs of formula $\left[\mathrm{Ni}\left(\mathrm{pyz}_{\mathrm{Z}}-\mathrm{NH}_{2}\right)_{2}\left(\mathrm{MF}_{6}\right)\right]_{\mathrm{n}}$ (pyz- $\mathrm{NH}_{2}=$ aminopyrazine, 17; M = Si, Ti), MFSIX-17-Ni [6]. Isostructural pyrazine analogues (SIFSIX-3-Zn [7], SIFSIX-3-Ni [8]) are the benchmark physisorbents for trace carbon capture but are unsuited for acetylene capture. No single physisorbent has the requisite selectivity to purify $\mathrm{C}_{2} \mathrm{H}_{4}$ from ternary $\mathrm{C}_{2}-\mathrm{CO}_{2}$ mixtures $\left(\mathrm{C}_{2} \mathrm{H}_{4} / \mathrm{C}_{2} \mathrm{H}_{2} / \mathrm{CO}_{2}\right)$ under ambient conditions until now. Indeed, both MFSIX-17-Ni sorbents produce polymer grade ethylene ( $>99.95 \%$ purity) from a 1:1:1 ternary mixture (Figure 1). Regarding insights for the future, we attribute the observed properties to the unusual binding sites in MFSIX-17-Ni that offer comparable affinity to both $\mathrm{CO}_{2}$ and $\mathrm{C}_{2} \mathrm{H}_{2}$, thereby enabling coadsorption of $\mathrm{C}_{2} \mathrm{H}_{2}$ and $\mathrm{CO}_{2}$. In situ synchrotron $\mathrm{x}$-ray diffraction, in situ IR spectroscopy and molecular modelling provide insight into these binding sites and why they differ from those of the pyrazine-linked materials.

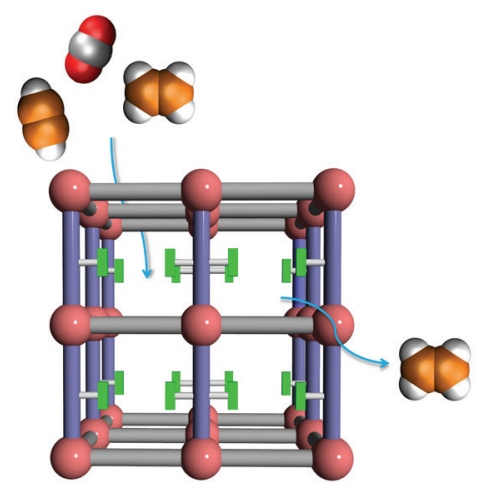

Figure 1. Schematic illustration of MFSIX-17-Ni that exhibits single-step $\mathrm{C}_{2} \mathrm{H}_{4}$ purification by simulatneous $\mathrm{CO}_{2}$ and $\mathrm{C}_{2} \mathrm{H}_{2}$ removal.

\section{Keywords: porous materials; crystal engineering; coordination networks; physisorption; ethylene purification}

S.M. acknowledges Prof. Roland A. Fischer for support and the Alexander von Humboldt foundation for funding.

[1] Kitagawa, S. (2015) Angew. Chem. Int. Ed. 54, 10686.

[2] Mukherjee, S. \& Zaworotko, M. J. (2020) Trends Chem. 2, 506.

[3] Cui, X., Chen, K., Xing, H., Yang, Q., Krishna, R., Bao, Z., Wu, H., Zhou, W., Dong, X., Han, Y., Li, B., Ren, Q., Zaworotko, M. J. \& Chen, B. (2016) Science 353, 141.

[4] Li, B., Cui, X., O'Nolan, D., Wen, H.-M., Jiang, M., Krishna, R., Wu, H., Lin, R.-B., Chen, Y.-S., Yuan, D., Xing, H., Zhou, W., Ren, Q., Qian, G., Zaworotko, M. J. \& Chen, B. (2017) Adv. Mater. 29, 1704210.

[5] Chen, K.-J.; Madden, D. G.; Mukherjee, S.; Pham, T.; Forrest, K. A.; Kumar, A.; Space, B.; Kong, J.; Zhang, Q.-Y. \& Zaworotko, M. J. (2019). Science 366, 241.

[6] Mukherjee, S., Kumar, N., Bezrukov, A. A., Tan, K., Pham, T., Forrest, K. A., Oyekan, K., Qazvini, O. T., Madden, D. G., Space, B. \& Zaworotko, M. (2021) Angew. Chem. Int. Ed. 60, 10902.

[7] Nugent, P., Belmabkhout, Y., Burd, S. D., Cairns, A. J., Luebke, R., Forrest, K., Pham, T., Ma, S., Space, B., Wojtas, L., Eddaoudi, M. \& Zaworotko, M. J. (2013) Nature 495, 80.

[8] Kumar, A., Madden, D. G., Lusi, M., Chen, K.-J., Daniels, E. A., Curtin, T., Perry IV, J. J. \& Zaworotko, M. J. (2015) Angew. Chem. Int.Ed. 54, 14372.

Acta Cryst. (2021), A77, C126 